\title{
Effect of aminophenols (5-ASA and 4-ASA) on colonic interleukin-1 generation
}

\author{
D Rachmilewitz, F Karmeli, L W Schwartz, P L Simon
}

\begin{abstract}
The effect of 5-ASA and 4-ASA, drugs used for the treatment of inflammatory bowel disease, on modulation of experimental colitis and on colonic generation of interleukin-1 was evaluated. Three weeks of treatment with 5-ASA or 4-ASA $(50 \mu \mathrm{g} / \mathrm{kg})$ and one week of treatment with 5-ASA significantly decreased colonic interleukin-1 generation and the extent and severity of inflammation in a rat model of colitis induced by trinitrobenzene sulphonic acid. Colonic biopsies were obtained from patients with active ulcerative colitis and organ cultured 24 hours in the absence or presence of the following drugs: sulphasalazine, sulphapyridine, 5-ASA and 4-ASA $(25-100 \mu \mathrm{g} / \mathrm{ml})$. Interleukin-1 content in tissue cultured in the presence of 5-ASA $(100 \mu \mathrm{g} / \mathrm{ml})$ was two-thirds of its content in tissue cultured in drug free medium and its release into the medium was decreased by $50 \%$. Sulphasalazine $50 \mu \mathrm{g} / \mathrm{ml}$ significantly decreased by $33 \%$ the tissue content but did not affect interleukin-1 release and a higher dose was not more effective. Sulphapyridine and 4-ASA in doses up to $100 \mu \mathrm{g} / \mathrm{ml}$ did not affect either interleukin-1 colonic content or its release into the culture medium. We conclude that pharmacological suppression of colonic interleukin-1 generation may be one, although not the sole mechanism to explain the therapeutic efficacy of 5-ASA in the treatment of inflammatory bowel disease.
\end{abstract}

Recent studies have suggested a possible role of interleukin-1 in the pathogenesis of inflammatory bowel disease and experimental colitis. Peripheral blood mononuclear cells of Crohn's disease patients were shown to produce in vitro high quantities of interleukin-1 compared with normal control cells ${ }^{1}$ and enhanced production of interleukin-1 beta was shown in colonic mononuclear cells of patients with inflammatory bowel disease. ${ }^{2}$ We have shown enhanced production of interleukin-1 by organ cultured colonic mucosa of patients with ulcerative colitis and Crohn's disease, ${ }^{3}$ most of which is derived from stimulated lamina propria mononuclear cells. ${ }^{4}$

Enhanced generation of colonic interleukin-1 was shown also in three models of experimental colitis: in the chronic rat model of trinitrobenzene sulphonic acid induced colitis ${ }^{5}$; in the rabbit immune complex colitis ${ }^{6}$; and in a rabbit model of acute colitis induced by enteropathogenic $E$ coli. ${ }^{7}$

In view of the enhanced colonic generation of interleukin-1 in models of experimental colitis and in patients with active inflammatory bowel disease and its possible contribution to the pathogenesis of the disease, it was logical to assume that drugs used in the treatment of inflammatory bowel disease may affect the generation of this cytokine. Corticosteroids which block interleukin-1 production by macrophages $^{8}$ were shown to inhibit its content as well as its release from the inflamed colonic mucosa of patients with ulcerative colitis. ${ }^{3} \mathrm{~A}$ dual cyclolipooxygenase inhibitor was shown to decrease colonic interleukin-1 synthesis in an experimental model of chronic colitis in rats.

The aim of the present study was to evaluate the possible modulation of experimental colitis by 5-ASA and 4-ASA and to determine the effect of sulphasalazine, its moieties, sulphapyridine and 5-ASA and 4-ASA on human colonic generation of interleukin-1 and, thus, to assess whether interference with its generation may be contributory to their therapeutic effects.

\section{Methods}

COLITIS INDUCTION IN RATS

All of the animal studies described in this report adhere to the standards established by the Guide for the care and use of laboratory animals (HHS NIH Pub No 85-21)

Non-fasted male Sprague Dawley rats, 200 $250 \mathrm{~g}$ body weight, were used. Inflammation of the colon was induced, as previously described, under light ether anaesthesia by a single intracolonic administration of $0.25 \mathrm{ml} 50 \%$ ethanol containing $30 \mathrm{mg}$ of trinitrobenzene sulphonic acid (Sigma, St Louis, MO, USA). The solution was introduced through a $0.3 \mathrm{~mm}$ (od) catheter at a distance of $7 \mathrm{~cm}$ from the anus. Rats were treated daily for one or three weeks after the induction of colonic injury with 5 -ASA $(50 \mathrm{mg} /$ $\mathrm{kg})$ or with $4-A S A(50 \mathrm{mg} / \mathrm{kg})$. Drugs were dissolved in $1 \%$ methylcellulose and were administered intragastrically. Control rats were treated intragastrically with $50 \mathrm{ml} / \mathrm{kg}$ of the vehicle (methylcellulose) daily. Rats were humanely killed one or three weeks after the induction of colonic injury. The colon was isolated, a $5 \mathrm{~cm}$ segment of the distal colon proximal to the anus was resected, its lumen rinsed with ice cold saline and weighed. A cross section was obtained for histology, fixed in phosphate buffered formaldehyde, embedded in paraffin and routine $5 \mu$ sections were prepared. Tissues were routinely stained with haematoxylin and eosin and evaluated by light microscopy. The remaining mucosa was scraped, minced and kept at $-70^{\circ} \mathrm{C}$. Samples of these mucosal scrapings were processed for determination of TxB2, LTB4, myeloperoxidase activity and interleukin-1 
DETERMINATION OF MYELOPEROXIDASE ACTIVITY AND EICOSANOIDS

Determination of myeloperoxidase activity and eicosanoids was carried out as previously described. ${ }^{5}$ In brief, for the determination of myeloperoxidase activity, $300 \mathrm{mg}$ mucosal scrapings were homogenised in $1.0 \mathrm{ml}$ ice cold $0.5 \%$ hexadecyltrimethylammonium bromide in 50 $\mathrm{mM}$ phosphate buffer, $\mathrm{pH} 6 \cdot 0$. The homogenate was sonicated for 10 seconds, freeze thawed three times and centrifuged for 15 minutes at $40000 \mathrm{~g}$. An aliquot of the supernatant was taken for determination of the enzyme activity according to Bradley et al. ${ }^{9}$ For the determination of eicosanoids, $100 \mathrm{mg}$ mucosal scrapings were homogenised in $1.0 \mathrm{ml} 50 \mathrm{mM}$ Tris $\mathrm{HCl}$ buffer, pH 7.4, containing $100 \mathrm{mM} \mathrm{NaCl}, 1 \mathrm{mM} \mathrm{CaCl} 2$ and $1 \mathrm{mg} / \mathrm{ml}$ of glucose. The homogenate was extracted with acetone and centrifuged at $1500 \mathrm{~g}$. The supernatant was extracted with ice cold petroleum ether and vortexed. The bottom layer was extracted with $3.0 \mathrm{ml}$ ice cold ethyl acetate, vortexed, and the top layer evaporated to dryness. TxB2 and LTB4 were determined using the 3H-RIA Seragen kit (Advance Magnetics, Cambridge, Mass, USA).

\section{STUDIES WITH HUMAN MUCOSAL SPECIMENS}

Mucosal tissue specimens were obtained during fibreoptic colonoscopy from inflamed sites in the rectosigmoid colon of patients with untreated active ulcerative colitis. The diagnosis of ulcerative colitis was established according to clinical, endoscopic, pathologic, and radiological criteria. In all patients clinical activity was manifested by bloody diarrhoea and verified histologically by the presence of mucosal ulceration, crypt abscesses, and infiltration with inflammatory cells. No subjects had received any medication for at least two weeks before the biopsies were obtained. The study protocol was approved by the local hospital's Helsinki Committee. Four to five tissue samples obtained from the same subject were incubated, each in a separate dish, immediately after excision in the absence or presence of sulphasalazine, sulphapyridine, 5-ASA (Pharmacia Laboratories, Uppsala, Sweden) or 4-ASA (Reed-Carnerick, New Jersey, USA) $25-100 \mu \mathrm{g} / \mathrm{ml}$. 5-ASA and sulphasalazine were dissolved in DMSO (stock solution $100 \mathrm{mg} / \mathrm{ml}$ ). Working dilutions were prepared in Roswell Park Memorial Institute (RPMI) medium, final $\mathrm{pH} 7 \cdot 5$ identical to that of RPMI. 4-ASA was dissolved in double distilled water. The specimens were cultured $\left(37^{\circ} \mathrm{C}, 5 \% \mathrm{CO}_{2}\right.$, $95 \%$ air) for 24 hours, as described earlier. ${ }^{10}$ In brief, the tissue was placed on a metal grid over the central well of the culture dish (Falcon) containing the culture medium which consisted of $0.7 \mathrm{ml} \mathrm{RPMI} 1640$ (BioLab, Israel) containing penicillin (100 IU/ml) and streptomycin (100 $\mu \mathrm{g} / \mathrm{ml})$.

\section{INTERLEUKIN-1 DETERMINATION}

Cultured human colonic specimens, average weight $10 \mathrm{mg}$, or $50 \mathrm{mg}$ of the rat colonic mucosal scrapings, were homogenised with a polytron homogeniser (Kinematic, Kriens-Lu, Switzer- land) for 20 seconds at a speed grade of 6 in 0.5

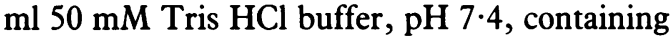
$100 \mathrm{mM} \mathrm{NaCl}, 1 \mathrm{mM} \mathrm{CaCl} 2$ and dextrose $(1 \mathrm{mg} /$ $1 \mathrm{ml}$ ). These samples, as well as the samples of the cultured medium, were kept at $-70^{\circ} \mathrm{C}$ until assayed for their interleukin-1 value.

Interleukin-1 activity was determined by its induction of interleukin-2 production by murine EL-4 cells as described previously." Briefly, $0.25 \mathrm{ml}$ cultures of $2 \times 10$ (5) EL-4 cells in a 96 well flat bottom plate are cocultured with the sample and $2 \times 10(-7) \mathrm{M}$ calcium ionophore A23187 for 24 hours. The culture fluids are then tested for interleukin-2 activity using the CTLL20 interleukin-2 dependent cell line. The interleukin-2 activity is directly proportional to the input of interleukin-1. Units of interleukin-1 activity were calculated relative to a standard of pure recombinant human interleukin-1 beta prepared as described previously, ${ }^{12}$ by a computer program described by Davis et al. ${ }^{13}$ All tissue extracts were centrifuged at $10000 \mathrm{~g}$ for three minutes and filter sterilised before assay.

\section{STATISTICAL ANALYSIS}

Statistical evaluation was performed according to the paired and unpaired Student's $t$ test.

\section{Results}

EFFECT OF DRUGS ON EXPERIMENTAL COLITIS

The effect of treatment was evaluated using the macroscopic criteria of ulceration, stenosis, adhesions, and colonic impaction. Modulation of colonic damage was observed in nine of 11 rats treated with 5-ASA and in eight of eight rats treated with 4-ASA. The affected colonic segment was narrow but there were usually no ulcerations, faecal impaction or adhesions to adjacent organs. Treatment with 4-ASA also resulted in a significant $(p<0.05)$ decrease in the wet weight of the affected segment $-0.71(0.06)$ $\mathrm{g}$ (mean (SEM)) as opposed to $1 \cdot 2(0 \cdot 14) \mathrm{g}$ in the control trinitrobenzene sulphonic acid/ethanol treated rats. In the 5-ASA treatment group, the wet weight was lower than in untreated rats but the difference did not reach statistical significance (Table I). After one week of treatment the severity of the trinitrobenzene sulphonic acid/ ethanol induced lesions was evaluated macroscopically to be reduced in six of eight 5-ASA treated rats. At this time interval the wet weight of the affected segment was reduced but this was not statistically significant (Table II). During treatment only one of 17 of the 5-ASA treated rats died after 10 days of treatment. None of the trinitrobenzene sulphonic acid/ethanol or 4-ASA treated rats died during the three week follow up period.

The effect of three weeks' drug treatment was evaluated histopathologically in 10 rats which served as untreated trinitrobenzene sulphonic acid $/ 50 \%$ ethanol injured subjects, and in 19 rats which received trinitrobenzene sulphonic acid/ $50 \%$ ethanol injury plus drug treatment. A single blind evaluation of the histopathological lesions resulted in the accurate identification of five of 10 untreated rats and identification of $16 / 19$ rats 
TABLE I Effect of three weeks of treatment with aminophenols on segment weight and inflammatory mediators

\begin{tabular}{lccc}
\hline & TNB/ethanol & $5-A S A$ & $4-A S A$ \\
\hline $\mathrm{n}$ & 18 & 11 & 8 \\
Weight $(\mathrm{g})$ & $1 \cdot 20(0 \cdot 14)$ & $0 \cdot 98(0 \cdot 13)$ & $0 \cdot 71(0 \cdot 06)^{\star}$ \\
Myeloperoxidase $(\mu / \mathrm{g})$ & $0 \cdot 97(0 \cdot 21)$ & $1 \cdot 04(0 \cdot 27)$ & $0 \cdot 65(0 \cdot 26)$ \\
LTB4 (ng/g) & $37 \cdot 50(3 \cdot 70)$ & $41 \cdot 70(3 \cdot 10)$ & $41 \cdot 80(2 \cdot 60)$ \\
TxB2(ng/g) & $146 \cdot 30(15 \cdot 00)$ & $145 \cdot 70(15 \cdot 30)$ & $166 \cdot 40(9 \cdot 80)$ \\
Interleukin-1 & $6815(1746)$ & $2360(720)^{\star}$ & $667(151)^{\star}$ \\
\hline
\end{tabular}

Colitis was induced by intracolonic administration of $0.25 \mathrm{ml} 50 \%$ ethanol containing $30 \mathrm{mg}$ trinitrobenzene sulphonic acid (TNB). Rats were treated daily with $5-A S A 50 \mathrm{mg} / \mathrm{kg}$ or $4-\mathrm{ASA} 50 \mathrm{mg}$ $\mathrm{kg}$. After three weeks of treatment rats were killed, a $5 \mathrm{~cm}$ colonic segment proximal to the anus was isolated, weighed, and the mucosa scraped for the determination of the inflammatory mediators, as described in Methods. Results are mean (SE)

$\star$ Significantly different from TNB/ethanol; $\mathrm{p}<0.05$.

which received drug treatment. This suggests that the reduction in lesion severity by drug treatment reduces lesion severity and allows its identification. A similar histological evaluation was completed of eight rats receiving 5-ASA for one week. Ten trinitrobenzene sulphonic acid/ $50 \%$ ethanol injured rats served as untreated controls. A single blind evaluation of the severity and extent of the histopathological changes after one week resulted in identification of seven of 10 untreated rats and accurate identification of five of eight treated rats, suggesting that one week of treatment with 5-ASA also reduced lesion severity.

Mucosal myeloperoxidase activity was not different in the control trinitrobenzene sulphonic acid/ethanol treated rats and in the 5-ASA and 4-ASA treatment groups (Tables I, II). The generation of the eicosanoids TxB2 and LTB4 was also not affected after three weeks of treatment with 5-ASA or 4-ASA, or after one week of treatment with 5-ASA (Tables I, II). On the other hand, after three weeks of therapy with 5-ASA and 4-ASA a significant decrease in mucosal interleukin-1 was observed when compared with trinitrobenzene sulphonic acid/ ethanol treated rats receiving no drugs (Table I). One week of treatment with 5-ASA reduced mucosal interleukin-1 levels but not significantly (Table II).

EFFECT OF DRUGS ON HUMAN COLONIC INTERLEUKIN-1

After 24 hours of culture, interleukin-1 content

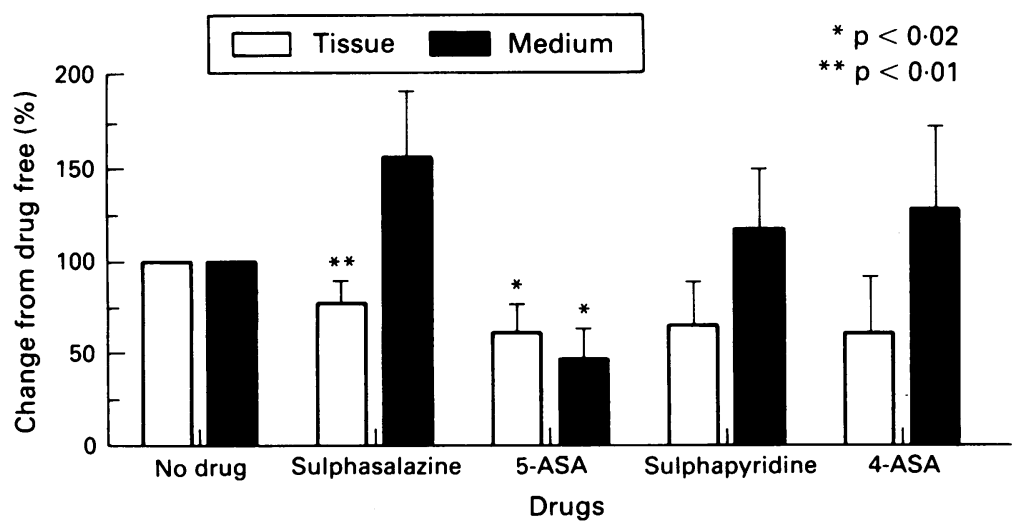

Effect of drugs on cultured human colonic content and release of interleukin-1. Colonic biopsies were obtained from patients with active ulcerative colitis and organ cultured for 24 hours in the were obtained from patients with active ulcerative colitis and organ cultured for 24 hours in
presence of sulphasalazine, sulphapyridine, $5-A S A$ or $4-A S A(100 \mu \mathrm{g} / \mathrm{ml})$. Interleukin-1 content and release in cultures conducted without drugs was $53(6)$ and $12 \cdot 4(1 \cdot 7)(n=12)$ units/ $m g$ wet weight respectively and regarded as $100 \%$. Significantly different from no drug. ${ }^{\star} p<0.01 ;{ }^{\star \star} p<0.02$.
TABLE II Effect of one week of treatment with 5-ASA on segment weight and inflammatory mediators

\begin{tabular}{lcc}
\hline & TNB/ethanol & $5-A S A$ \\
\hline n & 15 & 8 \\
Weight $(\mathbf{g})$ & $1 \cdot 99(0 \cdot 38)$ & $1 \cdot 20(0 \cdot 29)$ \\
Myeloperoxidase $(\mu / \mathrm{g})$ & $1.92(0 \cdot 64)$ & $2 \cdot 39(1 \cdot 71)$ \\
LTB4 $(\mathrm{ng} / \mathrm{g})$ & $47 \cdot 53(4 \cdot 38)$ & $40 \cdot 00(1 \cdot 87)$ \\
TxB2 $(\mathrm{ng} / \mathrm{g})$ & $121 \cdot 90(10 \cdot 50)$ & $101 \cdot 70(11 \cdot 30)$ \\
Interleukin-1 $(\mu / \mathrm{g})$ & $4276(1170)$ & $2713(1152)$ \\
\hline
\end{tabular}

Colitis was induced by intracolonic administration of $0.25 \mathrm{ml} 50 \%$ ethanol containing $30 \mathrm{mg}$ trinitrobenzene sulphonic acid (TNB) Rats were treated daily with 5 -ASA $50 \mathrm{mg} / \mathrm{kg}$. Control rats were treated with vehicle only. After one week of treatment rats were killed, a $5 \mathrm{~cm}$ colonic segment proximal to the anus was isolated weighed and the mucosa scraped for the determination of the inflammatory mediators, as described in Methods. Results are mean $(\mathrm{SE})$.

TABLE III Effect of 5-ASA and sulphasalazine on human colonic mucosal interleukin-content and release

\begin{tabular}{llrr}
\hline & \multicolumn{3}{c}{$\%$ Change } \\
\cline { 3 - 4 } Concentration $(\mu \mathrm{g} / \mathrm{ml})$ & Patients $(n)$ & Tissue & Medium \\
\hline $5-$ ASA: & & 100 & \\
0 & & $209(33)$ & $187(88)$ \\
25 & 5 & $118(45)$ & $75(25)$ \\
50 & 5 & $62(8) \dagger$ & $48(12) \dagger$ \\
100 & 4 & $113(28)$ & $77(12)$ \\
Sulphasalazine: & 5 & $67(8)^{\star}$ & $80(18)$ \\
25 & 6 & $78(5)^{\star}$ & $156(29)$ \\
50 & 6 & &
\end{tabular}

From each ulcerative colitis patient several mucosal specimen were obtained and cultured: one in the absence and one in each of the concentrations of sulphasalazine or $5-A S A(25-100 \mu \mathrm{g} / \mathrm{ml})$. Interleukin-1 content and release in cultures conducted without drugs was $51 \cdot 0(6 \cdot 6)$ and $14 \cdot 8(2 \cdot 4)(n=6)$ units/mg wet weight, respectively, and regarded as $100 \%$. Results are mean (SE). Significantly different from no drug. ${ }^{\star} \mathrm{p}<0.01 ; \mathrm{tp}<0.02$ ( $t$ test for paired data).

in the cultured tissue specimens was $53.0(6 \cdot 3)$ $\mu / \mathrm{mg}$ wet weight and its accumulation in the cultured medium was $12.4(1.7)$ units/mg wet weight $\times(\mathrm{SE})(\mathrm{n}=12)$. The effect of the drugs $(100 \mu \mathrm{g} / \mathrm{ml})$ on mucosal interleukin-1 content and on its release to the medium is presented in the Figure. Mucosal interleukin-1 content and its release in cultures conducted in drug free medium was regarded as $100 \%$. Only 5-ASA significantly decreased interleukin-1 colonic content and its release during 24 hours of culture. Interleukin-1 content in colonic mucosa cultured in the presence of 5-ASA was two-thirds of its content in tissue cultured in drug free medium. Interleukin-1 release into the medium containing 5-ASA was $50 \%$ of its release when cultured in drug free medium. 5-ASA concentrations lower than $100 \mu \mathrm{g} / \mathrm{ml}$ had no effect (Table III). Sulphasalazine $(50 \mu \mathrm{g} / \mathrm{ml})$ significantly decreased interleukin- 1 content but did not significantly affect its release into the medium. A higher concentration of $100 \mu \mathrm{g} / \mathrm{ml}$ did not further decrease the tissue content and also did not affect its release into the medium (Table III). Sulphapyridine and 4-ASA did not significantly affect either interleukin-1 content in the mucosa or its release into the culture medium.

\section{Discussion}

We have previously shown that the interleukin-1 bioassay used in the present study is in good correlation with an enzyme linked immunoadsorbent (ELISA) assay and that substances 
derived from the homogenisation did not interfere with the bioassay. ${ }^{3}$ Using this bioassay we have shown that colonic interleukin-1 generation is significantly increased in two models of experimental colonic inflammation and that interleukin-1 content in cultured mucosa of ulcerative colitis and Crohn's disease patients, and its release into the medium is several folds higher than their respective content and release by normal colonic mucosa. Prednisolone was found to decrease the human colonic tissue content of interleukin-1 and, even more effectively, to decrease its release into the medium during culture. ${ }^{3}$

In the present study, using the same methodology, 5-ASA was found to effectively decrease human colonic content of interleukin-1 and also to effectively decrease its release into the medium during culture. Similar observations were recently reported by Mahida et al.$^{14} 5$-ASA is the active moiety in salazopyrine ${ }^{15}$ and when administered by itself is effective in the treatment of mild to moderate active ulcerative colitis $^{16}$ and in the maintenance of the disease in remission. ${ }^{17}$ 5-ASA was previously shown to also inhibit the generation of human colonic prostanoids, ${ }^{10}$ leukotrienes, ${ }^{18}$ and the platelet activating factor - potential mechanisms to explain its therapeutic effects.

The injury induced by trinitrobenzene sulphonic acid/ethanol is definitely extensive. It is difficult to anticipate that any drug would be able to prevent the development of the inflammatory response to this severe insult, to modify its propagation or the generation of the inflammatory mediators. Yet, in the present study, 5-ASA was found to significantly affect interleukin-1 generation, although none of the other mediators determined - TxB2 and LTB4. In addition, the majority of rats treated with 5-ASA could be blindly identified, both macroscopically and histologically, indicating its therapeutic effect. It, therefore, seems that 5-ASA is a potent inhibitor of interleukin-1 generation, which may definitely contribute towards its antiinflammatory properties.

Sulphapyridine had no effect on human colonic interleukin-1 generation whereas sulphasalazine significantly decreased only its tissue content but did not affect its release. Sulphapyridine does not affect the generation of any of the other inflammatory mediators $\mathrm{s}^{10} 19$ and is not considered effective in the treatment of inflammatory bowel disease. ${ }^{15}$ Sulphasalazine, on the other hand, inhibits, although to a lesser extent than 5-ASA, the generation of colonic eicosanoids, ${ }^{10}$ and the platelet aggregation factor. ${ }^{19}$ As the therapeutic efficacy of sulphasalazine and 5-ASA is similar, ${ }^{16} 17$ it would appear that this efficacy cannot only be ascribed to their effects on one or all of the inflammatory mediators. Yet, if inhibition of the generation of inflammatory mediators is of importance only, 5-ASA share with corticosteroids ${ }^{20}$ significant inhibition of the colonic generation of prostanoids, ${ }^{10}$ leukotrienes, ${ }^{18}$ the platelet aggregation factor ${ }^{19}$ and, as herewith shown, also of interleukin-1.

4-ASA is also claimed to be of benefit in the treatment of ulcerative colitis. ${ }^{21}$ The mechanism responsible for its therapeutic efficacy is not well defined. In the present study it was found to modulate an experimental model of chronic colitis in which it significantly decreased colonic interleukin-1 generation but had no effect on human colonic interleukin-1 generation. The discrepancy between the effect of 4-ASA on human and rat colonic interleukin-1 generation casts doubts on the importance of blocking the generation of colonic interleukin-1 as the sole, important mechanism to explain the therapeutic effects of 4-ASA as well as the other drugs currently used for the treatment of inflammatory bowel disease.

1 Satsangi J, Wolstencroft RA, Cason J, Ainley CC, Dumonde CC, Thompson RPH. Interleukin 1 in Crohn's disease. Clin Exp Immunol 1987; 67: 594-605.

2 Mahida YR, Wu K, Jewell DP. Enhanced production of interleukin 1 by mononuclear cells isolated from mucosa with active ulcerative colitis and Crohn's disease. Gut 1989 30: 835-8.

3 Ligumsky M, Simon PL, Karmeli F, Rachmilewitz D. Role of interleukin-1 in inflammatory bowel disease - Enhanced interleukin-1 in inflammatory bowel disease - Enhance

4 Simon PL, West GA, Rachmilewitz D, Fiocchi C. Investigation of interleukin-1 (IL-1) activity in the intestinal mucosa tion of interleukin-1 (IL-1) activity in the intestinal mucosa
of Crohn's disease and ulcerative colitis patients [Abstract] of Crohn's disease and ulcerative

5 Rachmilewitz D, Simon PL, Schwartz LW, Griswold DE Fondacaro JD, Wasserman MA. Inflammatory mediators of experimental colitis in rats. Gastroenterology 1989; 97 326-37.

6 Cominelli F, Nast CC, Clark BD, Schindler R, Llerena R, Eysselein VE, et al. Interleukin-1 (IL-1) gene expression synthesis and effect of specific IL-1 receptor blockade in rabbit immune complex colitis. $\mathcal{f}$ Clin Invest 1990; 86: $972-$ 80.

7 Rachmilewitz D, Simon PL, Sjogren R, Fondacaro JD Wasserman MA, Boedeker E. Interleukin-1: A sensitive marker of experimental colitis [Abstract]. Gastroenterology marker of experi.

8 Snyder DS, Unanue ER. Corticosteroids inhibit murine macrophage Ia expression and interleukin-1 production. f Immunol 1982; 129: 1803 .

9 Bradley PP, Priebat DA, Christensen RD, Rothstein G Measurement of cutaneous inflammation: estimation of neutrophil content with an enzyme marker. $\mathcal{F}$ Inves Dermatol 1982; 78: 206-9.

10 Sharon P, Ligumsky M, Rachmilewitz D, Zor U. Role of prostaglandins in ulcerative colitis. Gastroenterology 1978; 75: $638-40$.

11 Simon PL, Laydon JT, Lee JC. A modified assay for interleukin-1 (IL-1). F Immunol Meth 1985; 84: 85-94.

12 Neyers CA, Johansen KO, Miles LM, McDevitt PJ, Simon PL, Webb RL, et al. Purification and characterization of PL, Webb RL, et al. Purification and characterization of human recom

13 Davis B, Huffman M, Knoblock K, Bader P. Logit analysis of interleukin-2 using a BASIC program. Comp Applicat Lab 1983; 4: 269-75

14 Mahida YR, Lamming CED, Gallagher A, Hawthorne AB Hawkey CJ. 5-Aminosalicylic acid is a potent inhibitor of interleukin 1-beta production in organ culture of colonic biopsy specimens from patients with inflammatory bowel disease. Gut 1991; 32: 50-4.

15 Azad Khan AK, Piris J, Truelove SC. An experiment to determine the active therapeutic moiety of sulphasalazine. determine the active ther
Lancet 1977; ii: $892-5$.

16 Rachmilewitz D. Coated mesalazine (5-aminosalicylic acid) versus sulphasalazine in the treatment of active ulcerative colitis: A randomized trial. $B M \mathcal{F} 1989 ; 298 ; 82-6$.

17 Rutgaerts P. Comparative efficacy of coated oral 5-aminosalicylic acid (claversal) and sulphasalazine for maintaining remission of ulcerative colitis. Aliment Pharmacol Thera 1989; 3: 183-91

18 Peskar BM, Dreyling KW, Peskar BA, May B, Goebell H. Enhanced formation of sulfidopeptide-leukotrienes in ulcerative colitis and Crohn's disease: inhibition of sulphasalazine and 5-aminosalicylic acid. Agents Actions 1986; 18 381-3.

19 Eliakim R, Karmeli F, Razin E, Rachmilewitz D. Role of platelet activating factor in ulcerative colitis. Gastroenterology 1988; 95: 1167-72.

20 Lauristen K, Staerk Laursen L, Bukhave K, Rask-Madsen J. In vivo effects of orally administered prednisolone on prostaglandin and leukotriene production in ulcerative prostaglandin and leukotrie

21 Ginsberg AL, Beck LS, McIntosh TM, Nochomovitz LE. Treatment of left sided ulcerative colitis with 4-aminoTreatment of left sided ulcerative colitis with 4-amino-
salicylic acid enemas: A double blind, placebo controlled trial. Ann Intern Med 1988; 108: 195-9. 